Original Article

\title{
The effect of soybean formula and formula 100 supplementation on the growth of preschool children
}

\author{
M Mexitalia, Yohanes Tri Nugroho, JC Susanto
}

\begin{abstract}
Background Preschool children are vulnerable in growth. Soybean formula (SF) and formula-100 (F100) are supplementary foods which contain of high energy and are available at low price; however, they are not widely used for preschool children.

Objectives To investigate the effect of SF compared to F100 on the growth of preschool children.

Methods A cross-over trial was conducted on 96 preschool children aged 4-7 years. Subjects were randomly divided into 2 groups which received $200 \mathrm{ml}$ soybean formula $(n=49)$ or $\mathrm{F} 100(n=47)$ for 1 month and crossed-over after a six-week wash-out period. Body weight was measured weekly. Body height and food analysis by $3-$ day food recall were measured at the beginning and the end of the study. The criteria of the acceptability of the formula was either good or poor.

Results Supplementation with SF as well as F100 induced catch up growth as shown by the increase of $\Delta z$-score. There were no significant difference of $\Delta$ weight for age z-score, $\Delta$ height for age z-score, and $\Delta$ weight for height $\mathrm{z}$ score between groups during the first and second phases of the trial. The acceptability of F100 was significantly better than that of SF at the beginning; nevertheless, the difference was not significant at the second phase trial.

Conclusions Soybean formula and F100 given for a one month period can induce catch-up growth in preschool children. Soybean formula as an alternative health food can be accepted by preschool children [Pediatr Indones 2005;45:256-263].
\end{abstract}

Keywords: soybean formula, formula 100, growth, preschool children
$\mathrm{M}$ oderate to severe wasting continues to be a public health problem in developing countries. In 1995, it has been estimated that $10.4 \%$ of preschool children in Southeast Asia were affected by wasting, ${ }^{1}$ but in China between 1991 1997 the prevalence of underweight was $13-14.5 \% .^{2}$ An analysis of changes in the levels of childhood undernourishment found that the prevalence of stunted preschool children in Southeast Asia declined from $37.7 \%$ in 1995 to $32.8 \%$ in 2000 and it is estimated to decline to $27.9 \%$ in 2005.3

Food supplement is available for children during their preschool years, and should prevents them from wasting. ${ }^{1}$ Only a few studies have been conducted on the importance of milk intake in preschool children, whereas milk is an important component for achieving the total recommended level of energy intake. ${ }^{4}$ Several studies on food supplement for catch-up the growth have been conducted in Jamaica on 24 monthold children in 1993, in Thailand on 36 month-old children, in West Java on 6-20 month-old children, ${ }^{5}$ and in Italy on 1-10 year-old children using Rinforza ${ }^{\circledR}{ }^{\circledR} 6$

From the Department of Child Health, Medical School, Diponegoro University, Kariadi Hospital, Semarang, Indonesia.

Reprint requests to: M. Mexitalia, MD, Department of Child Health, Jalan Dr. Sutomo 18, Semarang, Indonesia. Tel./Fax: 62-24-8414296. Email:maria_mexitalia@yahoo.com 
The conclusion is that food supplement is capable for catch-up growth.

Currently, in the market, there are soybean formulas (SF) and standard formula. In the beginning, SF was used as a substitute to feed babies with cow's milk allergy. The result is that these babies grew normally. Other studies indicate that regular consumption of soy protein may reduce risks associated with obesity. ${ }^{7-9}$

Formula-100 (F100) is often used during the rehabilitation phase of severe malnourished children. The formula is easily prepared, with basic ingredients of dried skimmed milk, sugar, cereal flour, oil, and mineral mix. The formula can also be made from dried whole milk or full cream milk with the same amount of density, i.e.100 $\mathrm{kcal} / 100 \mathrm{ml}$ and 2.9 grams protein/100 $\mathrm{ml} .{ }^{10,11}$ The use of F100 as well as SF as supplementation for normal children has not yet been reported. This study aimed to investigate the effect of SF compared to F100 on the growth of preschool children.

\section{Methods}

A randomized, cross-over trial was conducted on 3 kindergarten schools. Minimum samples needed for 2 groups were 92 children. The schools were selected from a list of those with moderate to low socioeconomic status in the North Semarang and Tembalang sub-districts of Semarang city. This study

Table 1. Subjects characteristics of SF (Group A) and F100 (Group B) In FIRST PHASE OF TRIAL (BEFORE WASH-OUT PERIOD)

\begin{tabular}{|c|c|c|c|}
\hline Characteristics & $\begin{array}{c}\text { SF } \\
(n=49)\end{array}$ & $\begin{array}{l}F 100 \\
(n=47)\end{array}$ & $\mathbf{P}$ \\
\hline Height, before (cm) & 109.6 & 105.4 & \\
\hline Height, after $(\mathrm{cm})$ & 110.0 & 105.9 & \\
\hline Increment of height gain $(\mathrm{cm})$ & 0.4 & 0.5 & $<0.001^{*}$ \\
\hline Weight, before $(\mathrm{kg})$ & 16.7 & 15.3 & \\
\hline Weight, after (kg) & 16.9 & 15.5 & \\
\hline Increment of weight gain $(\mathrm{kg})$ & 0.2 & 0.2 & 0.8 \\
\hline WAZ, before (SD) & -1.41 & -1.57 & \\
\hline WAZ, after (SD) & -1.38 & -1.54 & \\
\hline Increment of WAZ gain & 0.03 & 0.03 & 0.7 \\
\hline $\mathrm{HAZ}$, before (SD) & -1.09 & -1.68 & \\
\hline HAZ, after (SD) & -1.08 & -1.65 & \\
\hline Increment of $\mathrm{HAZ}$ gain & 0.01 & 0.03 & 0.6 \\
\hline WHZ, before (SD) & -1.04 & -0.72 & \\
\hline WHZ, after (SD) & -0.99 & -0.69 & \\
\hline Increment of WHZ gain & 0.05 & 0.03 & 0.7 \\
\hline Energy intake, before (kcal/day) & 1182 & 1200 & \\
\hline Energy intake, after (kcal/day) & 1374 & 1352 & \\
\hline Increment of energy intake (kcal/day) & 192 & 152 & 0.4 \\
\hline Protein intake, before (grams/day) & 37.1 & 35.5 & \\
\hline Protein intake, after (grams/day) & 44.4 & 38.6 & \\
\hline Increment of protein intake (grams/day) & 7.2 & 3.1 & $0.03^{*}$ \\
\hline \%RDA energy intake, before (kcal/day) & 98 & 84 & \\
\hline \%RDA energy intake, after (kcal/day) & 106 & 96 & \\
\hline Increment of \%RDA energy intake (kcal/day) & 8 & 12 & 0.3 \\
\hline$\%$ RDA protein intake, before (grams/day) & 155 & 136 & \\
\hline \%RDA energy intake, after (grams/day) & 162 & 148 & \\
\hline Increment of \%RDA energy intake (grams/day) & 7 & 12 & 0.6 \\
\hline \multirow{2}{*}{$\begin{aligned} \text { Acceptability: } & \text { Poor }(\%) \\
& \text { Good (\%) }\end{aligned}$} & 21 & 3 & \\
\hline & 28 & 44 & $<0.001^{*}$ \\
\hline
\end{tabular}

Note:

WAZ: weight for age $z$ score

$H A Z$ : height for age $z$ score

WHZ: weight for height $\mathrm{z}$ score

* Statistically significant
RDA: recommended dietary allowance

Acceptability: Good $>50 \%$ intake

Poor $<50 \%$ intake 
Table 2. Subjects characteristics on SF (group B) and F100 (group A) IN SECOND PHASE OF TRIAL (AFTER WASH-OUT)

\begin{tabular}{|c|c|c|c|}
\hline Characteristics & $\begin{array}{c}\text { SF } \\
(n=47)\end{array}$ & $\begin{array}{c}F 100 \\
(n=49)\end{array}$ & $\mathbf{P}$ \\
\hline Height, before $(\mathrm{cm})$ & 106.1 & 113.1 & \\
\hline Height, after (cm) & 106.5 & 110.6 & \\
\hline Increment of height gain (cm) & 0.4 & 0.5 & 0.1 \\
\hline Weight, before $(\mathrm{kg})$ & 15.5 & 16.9 & \\
\hline Weight, before $(\mathrm{kg})$ & 15.9 & 17.3 & \\
\hline Increment of weight gain (kg) & 0.4 & 0.4 & 0.9 \\
\hline WAZ, before (SD) & -1.59 & -1.40 & \\
\hline WAZ, after (SD) & -1.49 & -1.26 & \\
\hline Increment of WAZ gain & 0.10 & 0.14 & 0.6 \\
\hline $\mathrm{HAZ}$, before (SD) & -1.64 & -1.11 & \\
\hline $\mathrm{HAZ}$, after (SD) & -1.61 & -1.09 & \\
\hline Increment of HAZ gain & 0.03 & 0.02 & 0.9 \\
\hline WHZ, before (SD) & -0.77 & -1.00 & \\
\hline WHZ, after (SD) & -0.61 & -0.80 & \\
\hline Increment of $\mathrm{WHZ}$ gain & 0.16 & 0.2 & 0.7 \\
\hline Energy intake, before (kcal/day) & 1407 & 1341 & \\
\hline Energy intake, after (kcal/day) & 1515 & 1441 & \\
\hline Increment of energy intake (kcal/day) & 108 & 100 & 0.9 \\
\hline Protein intake, before (grams/day) & 40.3 & 41.4 & \\
\hline Protein intake, after (grams/day) & 44.1 & 43.2 & \\
\hline Increment of protein intake (grams/day) & 3.8 & 1.8 & 0.4 \\
\hline \%RDA energy intake, before (kcal/day) & 84.7 & 148 & \\
\hline$\%$ RDA energy intake, after (kcal/day) & 93.3 & 160 & \\
\hline Increment of \%RDA energy intake (kcal/day) & 8.6 & 12 & 0.6 \\
\hline$\%$ RDA protein intake, before (grams/day) & 134 & 150 & \\
\hline$\%$ RDA energy intake, after (grams/day) & 140 & 161 & \\
\hline Increment of \%RDA energy intake (grams/day) & 6 & 11 & 0.5 \\
\hline \multirow{2}{*}{ Acceptability: Poor (\%) } & 11 & 6 & \\
\hline & 36 & 43 & 0.2 \\
\hline \multicolumn{4}{|c|}{ 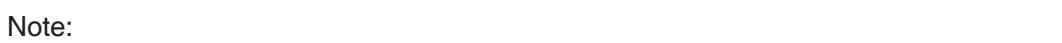 } \\
\hline \multicolumn{4}{|c|}{ RDA: recommended dietary allowance } \\
\hline HAZ: height for age z score & \multicolumn{3}{|c|}{ Acceptability: Good $>50 \%$ intake } \\
\hline WHZ: weight for height $z$ score & \multicolumn{3}{|c|}{ Poor $<50 \%$ intake } \\
\hline
\end{tabular}

was approved by the Ethical Clearance Committee prior to the study. Written informed consent was obtained from each child's parents or legal guardian prior to enrollment.

There were 96 preschool children aged 4-7 years included in this study. The subjects were divided into two groups. Group A (Tembalang) received SF for one month, followed by a six-week wash-out period and then followed by F100 for one month. Group B (North Semarang) received F100 for one month, followed by a six-week wash-out period and then continued SF for one month. No formula was given during washout period.

Milk (SF or F100) was prepared by dieticians who were trained by the investigators, then measured, and afterwards distributed by cup with name tag. Each child received $200 \mathrm{ml}$ of milk everyday. Intake and acceptability were measured to the nearest $25 \mathrm{ml}$ of each child everyday. Acceptability was good if the children drank more than $50 \%$ of the milk and poor if they drank less than $50 \%$ of milk.

Body weight was measured weekly by CEBA electronic weighing scale. Height was measured by microtoise during the first and last day of each phase. These data were plotted on the WHO-NCHS $z$ score. The social economy status was measured by Bistok Saing Scale. The parents or caregivers were asked to complete the questionnaires and a recall of food for 3 days. Children with allergy, intolerance, severe malnutrition, obesity, severe infection, and handicap were excluded. Children who were absent from school for more than 5 days were considered drop-outs. The $\Delta$ weight 
for age $z$ score ( $\Delta$ WAZ), $\Delta$ height for age $z$ score ( $\Delta \mathrm{HAZ}$ ), and $\Delta$ weight for age $\mathrm{z}$ score $(\Delta \mathrm{WHZ})$ between groups were compared by Student $t$-test or MannWhitney test when the data was not normally distributed. Difference of acceptance level was analyzed by chsquare test. $\mathrm{P}<0.05$ was considered as significant.

\section{Results}

The study was conducted in 2 phases, the first phase was before the wash-out period and the second one was after it. One hundred and thirteen children aged 4-7 years were enrolled. During the first phase, 17 children dropped-out due to moving to another school, 7 children refused to participate and 10 children were absent from school for more than 5 days. Therefore there were only 96 children left in the study (49 boys and 47 girls). At the second phase, all 96 children completed the study. Forty-nine children belonged to group A who received SF followed by F100 after wash-out, and 47 children belonged to group B

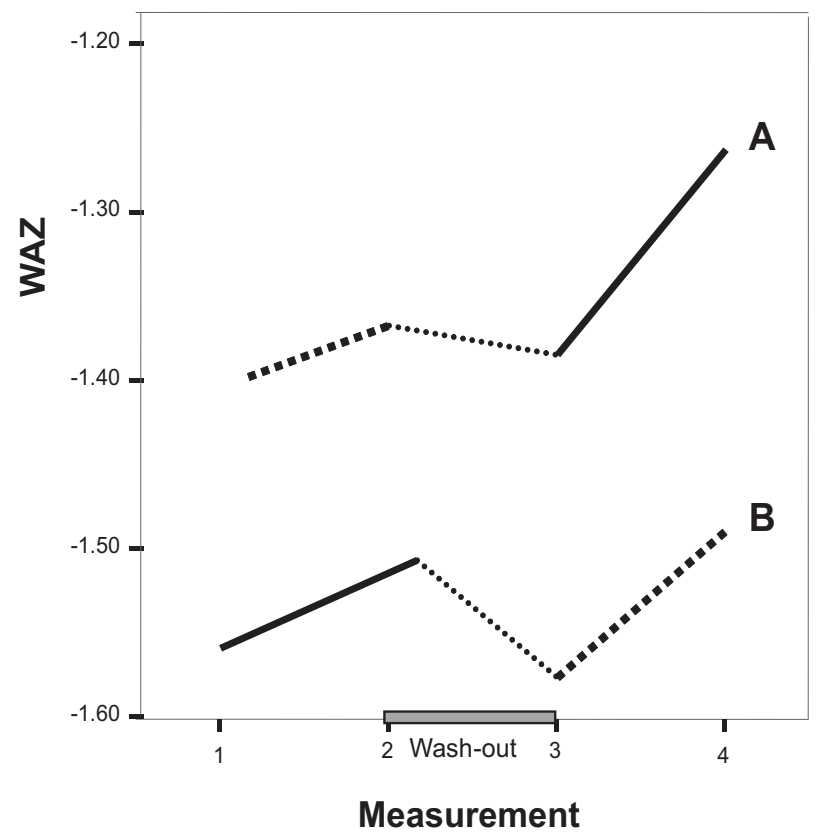

Figure 1. Growth measured by WAZ during SUPPLEMENTATION AND WASH-OUT PERIOD. BOLD-DASHED LINE REPRESENTS SF GROUP AND INTACT LINE REPRESENTS F100 GROUP. who received F100 at the first phase followed by SF after wash-out. The mean age of the children was 67 months. Using Bistok Saing Scale for socioeconomic status, $42.7 \%$ were of low socioeconomic status, $46.9 \%$ of moderate socioeconomic status, and $10.4 \%$ of high socioeconomic status.

The characteristics of the children at the first phase is shown on Table 1, where 49 children from group A received SF and 47 children from group B received F100, both groups for one month. There was an increase of growth in both groups. Statistical analysis showed that there was no significant difference either in weight gain or in increment of WHZ, WAZ, and HAZ (P>0.05). On the other hand, F100 supplementation was better compared to the SF regarding the child height gain $(0.5 \mathrm{~cm}$ versus $0.4 \mathrm{~cm}, \mathrm{P}<0.05)$. Protein intake of the SF was 7.2 grams/day significantly higher than that of F100 group which was 3.1 grams/ day $(\mathrm{P}<0.05)$. The increment also depended on the energy intake, \% recommended dietary allowance (RDA) energy intake and \%RDA protein intake, but was not statistically significant. The acceptability of

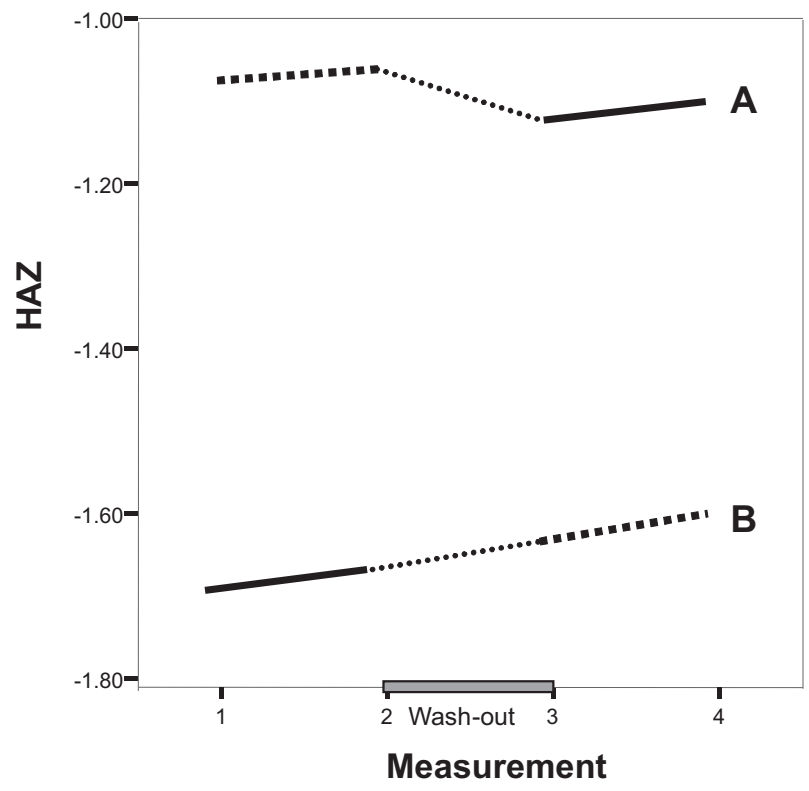

Figure 2. Growth measured by haZ during SUPPLEMENTATION AND WASH-OUT PERIOD. BOLD-DASHED LINE REPRESENTS SF GROUP AND INTACT LINE REPRESENTS F100 GROUP. 


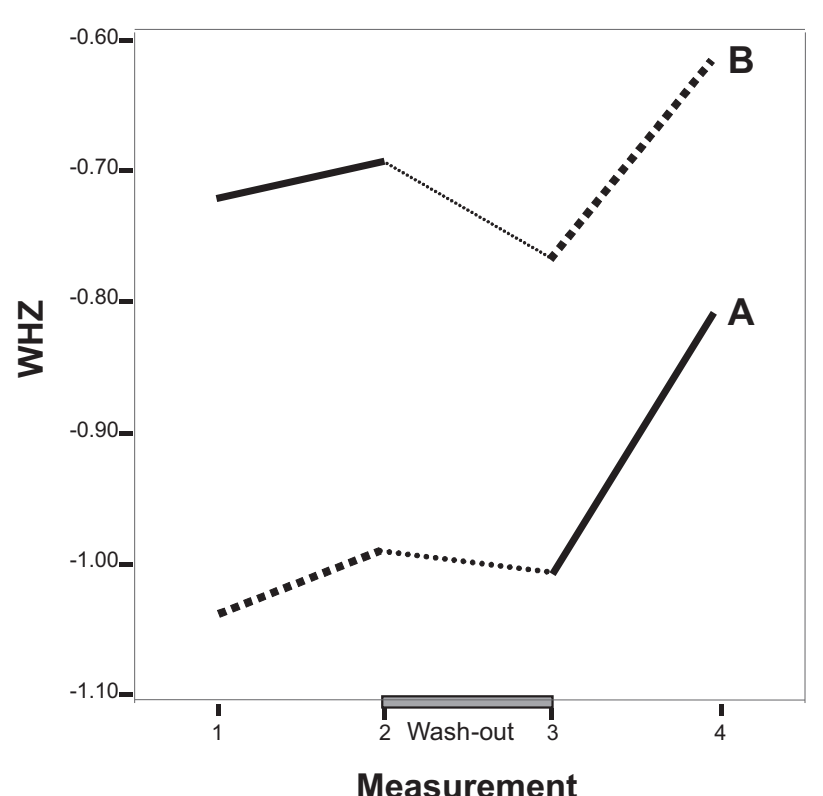

Figure 3. Growth measured by WHZ during SUPPLEMENTATION AND WASH-OUT PERIOD. BOLD-DASHED LINE REPRESENTS SF GROUP AND INTACT LINE REPRESENTS F100 GROUP.

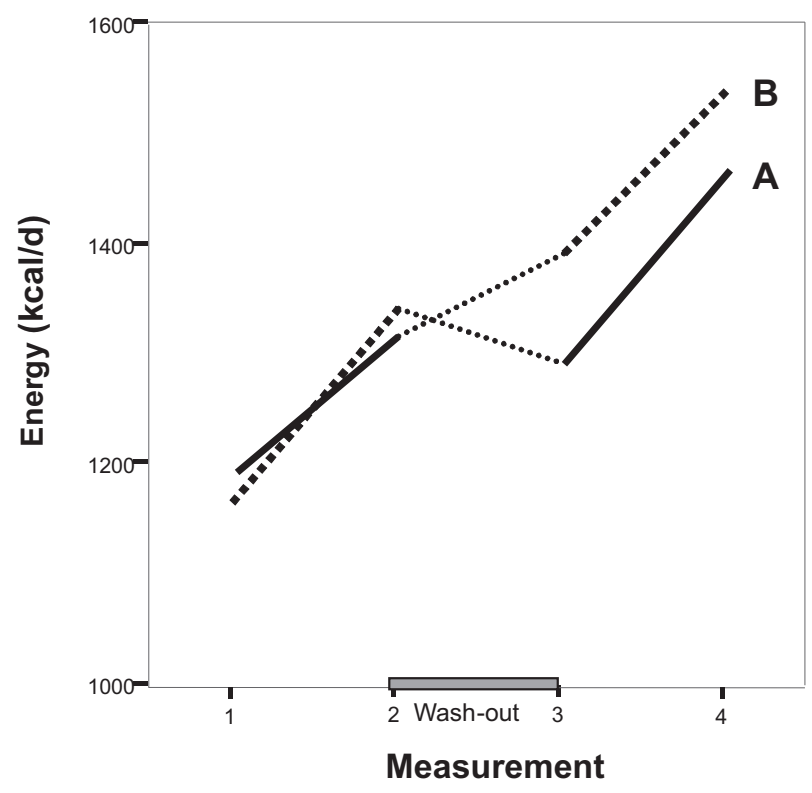

Figure 4. ENERgy INTAKE DURING SUPPLEMENTATION AND WASH-OUT PERIOD. BOLD-DASHED LINE REPRESENTS SF GROUP AND INTACT LINE REPRESENTS F100 GROUP.

F100 was significantly better compared to SF on the first phase $(\mathrm{P}<0.001)$.

In the second phase after a six-week wash-out period, 49 children from group A received F100 and

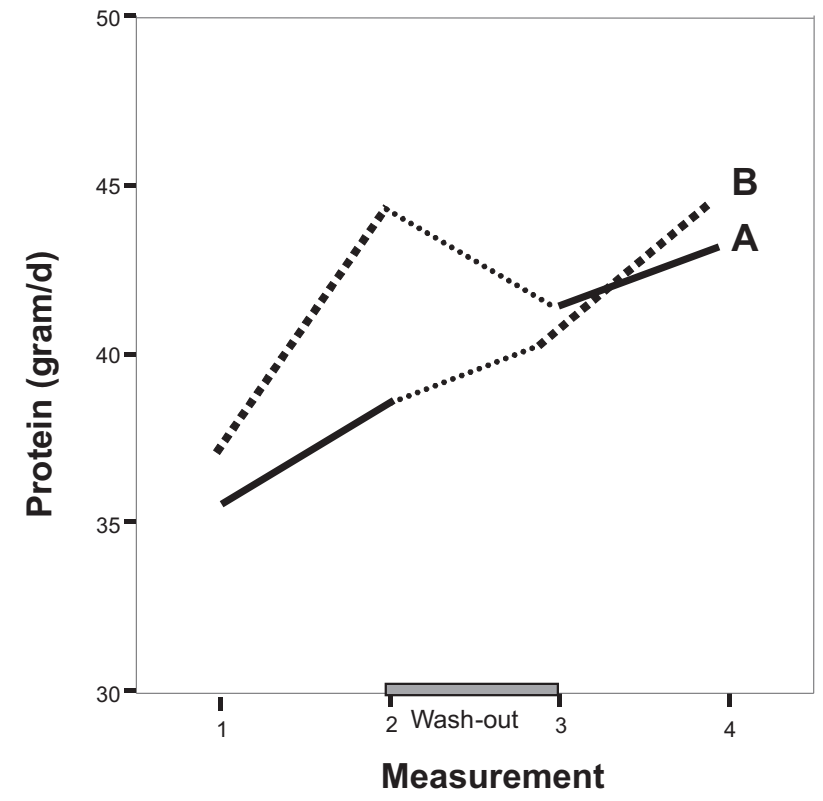

Figure 5. DaILY PROTEIN INTAKE DURING SUPPLEMENTATION AND WASH-OUT PERIOD. BOLD-DASHED LINE REPRESENTS SF GROUP AND INTACT LINE REPRESENTS F100 GROUP.

47 children from group B received SF for one month. There was an increase in growth, energy, and protein intake, as well as \%RDA for both energy and protein in both groups. But the analysis showed no significant difference. It also showed that there was no significant difference in the acceptability between F100 and SF.

Figure 1,2,3,4, and 5 show that in group A, the WAZ, HAZ, and WHZ, energy and protein intake, respectively, increased during the supplementation, both before and after wash-out. During the washout period, the WAZ, HAZ, WHZ, energy and protein intake decreased. In group B, the WAZ and WHZ increased during supplementation but decreased during the wash-out period. Meanwhile, the HAZ, energy and protein both increased during supplementation period as well as during the wash-out period.

Figure 4 and Figure 5 show that in group B, an increase of energy intake and protein intake occurred both during supplementation and wash-out period, but the increase is lower during the wash-out period. While in the group A, there was an increase during supplementation but during wash-out period, it decreased.

No harmful effect was found in F100 as well as SF supplementation. 
M Mexitalia et al.: The effect of soybean formula and formula 100 supplementation

\section{Discussion}

Supplementation with SF as well as F100 induced catch-up growth shown by the increase of $\Delta z$-score. At the first phase, supplementation with SF for one month increased weight by 200 grams, height $0.4 \mathrm{~cm}$, $\Delta$ WAZ 0.03, $\triangle$ HAZ 0.01, and $\triangle \mathrm{WHZ} \mathrm{0.05.} \mathrm{On} \mathrm{the}$ other hand, supplementation with F100 caused weight gain 200 grams, height $0.5 \mathrm{~cm}, \Delta \mathrm{WAZ} 0.03, \Delta \mathrm{HAZ}$ 0.03 , and $\Delta \mathrm{WHZ} 0.03$. At the second phase, after the wash-out the increase was better. The weight gain in SF supplementation group was 400 grams, height gain $0.4 \mathrm{~cm}, \Delta \mathrm{WAZ}$ was $0.10, \Delta \mathrm{HAZ}$ was 0.03 , and $\Delta \mathrm{WHZ}$ was 0.16 . Supplementation with F100 gained weight by 400 grams, height $0,5 \mathrm{~cm}, \Delta \mathrm{WAZ} 0.14, \Delta \mathrm{HAZ} 0.02$, and $\triangle$ WHZ 0.20.

Many studies about supplementation which involved children older than three years did not show accelerated catch up growth. ${ }^{1}$ Supplementation with high fat or high carbohydrate biscuits given to 30 stunted but not wasted Gambian children 3-9 years of age also induced catch-up growth. Each children received biscuits containing approximately $1600 \mathrm{~kJ}$ for as long as 12 months. The results showed that neither fat nor carbohydrate supplement had a significant influence on growth. The high fat supplement did slightly increase adipose tissue mass. The reasons for this remains unclear. ${ }^{12}$ Meanwhile, in Italy, a 4-month supplementation with Rinforza ${ }^{\circledR}$ (Pediasure ${ }^{\circledR}$ ) of 174 children aged 12 months to 10 years showed a decrease of risk for malnutrition (weight-for-height below the $25^{\text {th }}$ percentile). Although the differences were not statistically significant after 2 months, they were statistically significant after 4 months. ${ }^{4}$ Our study showed good results after a one-month supplementation with SF and F100. In Guatemala, a 6-month supplementation with Atole ${ }^{\circledR}$ (a drink with high protein and moderate energy content) on children aged 6-24 months with weight-for-length between $90 \%$ and $99.9 \%$, showed significantly good results in preventing malnutrition (the attributable prevention ranged from 0.21 to 0.26 ). Meanwhile, there was only little effect of Atole ${ }^{\circledR}$ in the older age group (24-48 months). The attributable prevention values ranged between 0.06 and 0.11 .1 Another study of a 4-month oral nutritional supplementation with or without synbiotics in children aged 1-6 years old, showed that both could induce catch-up growth and prevent malnutrition. ${ }^{13}$
In our study, the increase of energy and protein intake was also good. The increase of the energy intake from RDA of FS group before the wash-out was an $8 \%$ increase of energy intake and $7 \%$ of protein intake. From F100, before wash-out was $12 \%$ and protein intake was $12 \%$. After the wash-out, increase of energy and protein intake were $8.6 \%$ and $6 \%$, respectively, using SF supplementation and $12 \%$ energy intake and $11 \%$ energy intake using SF. In Sweden, the role of milk in preschool lunch meals has been debated frequently and water is often alternatively given. A study was done on 36 children aged 4-6 years, and water or milk was served alternatively. When milk was given with meals, a mean additional energy intake of $17 \%(\mathrm{P}<0.0001)$ was found. ${ }^{4}$ In USA, traditional and soy-enhanced lunches were randomly assigned to respective days on preschool children aged 3-6 years. There were no significant differences in energy values served for traditional compared to soy-enhanced lunches. However, protein was significantly higher in the soy-enhanced lunches, ${ }^{8}$ which was similar to our study.

Food supplementation can influence energy and protein intake. During the wash-out period, the intake of energy and protein was less or even decreased. A study in Iran, which assessed the impact of nutritional education on growth, found that educational interventions involving parents and/ or other family members might play a role in increasing the children's energy and protein intake. Therefore, it is important to give supplementation as well as nutritional education, ${ }^{14}$ which was not done in our study.

There was no significant difference in catch-up growth which was measured by means of $\Delta \mathrm{WAZ}$, $\Delta \mathrm{HAZ}$, and $\Delta \mathrm{WHZ}$ between SF and F100 group. There was also no significant difference between energy intake, however protein intake before the washout period was significantly different. The increase of protein intake was not followed by the difference in growth. This maybe due to the Protein Efficacy Ratio (PER) of soybean 2.3 while cow milk formula 2.5 and the Net Protein Utilization (NPU) Formula 63 while cow's milk formula 80.9 The Food and Agriculture Organization of the United Nations has established an amino acid requirement pattern based on the requirements for indispensable amino acids for each age group. This pattern can be used as a standard of com- 
parison in roughly assessing the quality of food proteins and protein mixtures by calculating an amino acid score. The amino acid score of cow's milk is 100 and soybean is $82 .{ }^{14}$ Soybean had a good protein energy ratio of 19.1 as well as cow's milk 20.3, ${ }^{15}$ however, the total nitrogen loss of soybean is higher than that of cow's milk. ${ }^{16}$ The digestibility coefficient of total nitrogen in soybean 0.90 , meanwhile cow's milk 0.95. 17

The acceptability of F100 is better than that of soybean formula with significant difference before the wash-out period. After the wash-out period there was no significant difference of acceptability. Although F100 was more acceptable, there is no significant difference in inducing the catch-up growth of the children. The change in food acceptance develops slowly in young children, with numerous exposures necessarily before clear acceptance is shown ${ }^{8}$ and it is strongly tracked over periods of 19 months to more than 6 years. ${ }^{18}$ Preschoolers are still developing taste and smell preferences for that they may be more likely to try and accept soy products more than older children which is why introducing soybean formula as an alternative healthy feeding to this population may be successful in establishing a preference for health-promoting foods. 8

In conclusion, soybean formula and F100 given for a-one-month period can induce catch-up growth in preschool children. Soybean formula as an alternative to health food can be accepted by preschool children.

\section{Acknowledgments}

We are grateful to Otsuka Co. Ltd, Indonesia for support on research conducting. We thank Mrs. Tatik Mulyati, DCN, MKes from Department of Nutrition, Kariadi Hospital for assisting on diet preparation, and Hardian, MD from Department of Physiology, Medical School, Diponegoro University for his contribution to statistical analysis.

\section{References}

1. Rivera JA, Habicht JP. Effect of supplementary feeding on the prevention of mild-to-moderate wasting in conditions of endemic malnutrition in Guatemala. Bulletin of the WHO 2002;80:926-32.
2. Wang Y, Monteiro C, Papkin B M. Trends of obesity and underweight in older children and adolescens in United States, Brazil, China and Russia. Am J Clin Nutr 2002;75:971-2.

3. De Onis M, Frongillo EA, Blossner M. Is malnutrition declining? An analysis of changes in levels of child malnutrition since 1980. Bulletin of the WHO 2000;78:122233.

4. Hägg A, Jacobson T, Nordlund G, Rössner S. Effects of milk or water on lunch intake in preschool children. J Appetite 1998;31:83-92.

5. WHO. Complementary feeding of young children in developing countries: A review of current scientific knowledge. Geneva; 1998.

6. Fiore P, Castagnola E, Merolla R. Effect of nutritional intervention on physical growth in children at risk of malnutrition. Int Ped 2002;17:179-83.

7. Businco L, Bruno G, Giampietro PG. Soy protein for the prevention and treatment of children with cowmilk allergy. Am J Clin Nutr 1998;68(Suppl):1447S52S.

8. Endres J, Barter S, Theodora P, Welch P. Soy-enhanced lunch acceptance by preschoolers. J Am Diet Assoc 2003;103:346-51.

9. Klish WJ. Soy protein-based formulas: Recommendation for use in infant feeding. Am Acad Ped 1998;102: 148-53.

10. WHO. Management of severe malnutrition: A manual for physicians and other senior health workers. Geneva; 1999.

11. WHO. Introduction: Management of severe malnutrition. Geneva; 2000.

12. Krähenbühl JD, Schutz Y, Jëquier E. High fat versus high carbohydrate nutritional supplementation: A one year trial in stunted rural Gambian children. Eur J Clin Nutr 1998;50:213-22.

13. Fisberg M, Maulén-Radován IE, Tormo R, Carrascoso MT, Giner CP, Martin FA, et al. Effect of oral nutritional supplementation with or without synbiotics on sickness and catch-up growth in preschool children. Int Pediatr 2002;17:216-22.

14. Salehi M, Kimiagar SM, Shahbazi M, Mehrabi Y, Kolahi AA. Assessing the impact of nutrition education on growth indices of Iranian nomadic children: An application of modified beliefs, attitudes, subjective-norms, and enabling-factors model. Br J Nutr 2004;91:779. 87.

15. Mahan LK, Arlin MT. Krause's food, nutrition, and 
M Mexitalia et al.: The effect of soybean formula and formula 100 supplementation

diet therapy. 8th ed. Philadelphia: WB Saunders Co.; 1992. p. 64-9.

16. Prawirohartono EP. Nutrien dan angka kecukupan gizi yang dianjurkan. 1st ed. Yogyakarta: BP-FK UGM; 1997. p. 1-19.
17. Tome D, Bos C. Dietary protein and nitrogen utilization. J Nutr 2000;130:1868S-73S.

18. Skinner JD, Ziegler P, Ponza M. Transitions in infants' and toddlers' beverage patterns. J Am Diet Assoc 2004;104:S45-50. 